\title{
Transrectal Ultrasound Guided Biopsy of the Prostate: Is the Information Accessible, Usable, Reliable and Readable?
}

\author{
Ciaran E. Redmond ${ }^{\mathrm{a}} \quad$ Gregory J. Nason ${ }^{\mathrm{a}} \quad$ Michael E. Kelly $^{\mathrm{a}}$ \\ Colm McMahon $^{\mathrm{b}}$ Colin P. Cantwell ${ }^{\mathrm{b}}$ David M. Quinlan ${ }^{\mathrm{a}}$ \\ Departments of aUrology and ${ }^{\text {b} R a d i o l o g y, ~ S t ~ V i n c e n t ' s ~ U n i v e r s i t y ~ H o s p i t a l, ~ D u b l i n, ~ I r e l a n d ~}$
}

\section{Key Words}

Prostate biopsy $\cdot$ Quality $\cdot$ Readability $\cdot$ Internet

\begin{abstract}
Background/Aims: To evaluate the accessibility, usability, reliability and readability of Internet information regarding transrectal ultrasound (TRUS) guided biopsy of the prostate. Materials and Methods: The terms "prostate biopsy", "TRUS biopsy" and "transrectal ultrasound guided biopsy of the prostate" were separately entered into the each of the top 5 most accessed Internet search engines. Websites were evaluated for accessibility, usability and reliability using the LIDA tool - a validated tool for the assessment of health related websites. Website readability was assessed using the Flesch Reading Ease Score and the Flesch Kincaid Grade Level. Results: Following the application of exclusion criteria, 82 unique websites were analyzed. There was a significant difference in scores depending on authorship categories $(p \leq 0.001)$, with health related charity websites scoring highest (mean $122.29 \pm 13.98$ ) and non-academic affiliated institution websites scoring lowest (mean $87 \pm$ 19.76). The presence of advertisements on a website was associated with a lower mean overall LIDA tool score $(p=0.024)$. Only a single website adhered to the National Institutes for Health recommendations on readability. Conclusions: This study demonstrates variability in the quality of information avail-
\end{abstract}

\section{KARGER}

Fax +4161306 1234

E-Mail karger@karger.ch

www.karger.com
(C) 2014 S. Karger AG, Basel

1015-9770/14/0081-0032\$38.00/0

Accessible online at:

www.karger.com/cur able to Internet users regarding TRUS biopsies. Collaboration of website design and clinical acumen are necessary to develop appropriate websites for patient benefit.

Copyright $\odot 2014$ S. Karger AG, Basel

\section{Introduction}

With the exponential growth of the Internet, there is an abundance of freely accessible health related information available to the general public. This has resulted in a transformation of the medical information landscape [1]. Patients are now more informed about their medical condition and available treatment options through online self-education. A recent survey observed that $59 \%$ of American adults had utilized the Internet in search of health information in the previous year [2].

Ideally the Internet would provide patients access to current and reliable information that is easy to read and comprehend. However, the majority of the content freely available is unregulated and with no peer review. Recent studies have raised concerns regarding both the quality and readability of online information regarding common medical conditions and treatments [3-5]. Unfortunately, it has been shown that $86 \%$ of users believed the online health information they read [6]. The information avail-

Ciaran E. Redmond

Department of Urology, St Vincent's University Hospital

Elm Park, Dublin 4, Ireland

E-Mail ciaranredmond1@gmail.com 
able to patients online has been shown to influence their perception of medical conditions and affect their treatment decisions $[7,8]$. It is important for physicians to be aware of this online information, in order to be able to understand patients' possible misinformation and confusion regarding a medical condition. If physicians are unaware or fail to acknowledge this, they risk alienating patients as a result [9]. We believe that the Internet should be utilized effectively to educate patients. However, direction to suitable and verified websites with regulated information is required [10].

The transrectal approach for prostate biopsy was first described in 1937 [11] and today Transrectal ultrasound (TRUS) guided biopsy of the prostate is a commonly used method to diagnose prostate cancer [12]. Over 1 million TRUS biopsies are estimated to be performed annually in the United States of America (USA) [13]. A TRUS biopsy is carried out by an urologist or radiologist as an outpatient procedure. The main complications include urosepsis, hematuria, hematospermia, and hematocheiza [14].

The aim of this study was to evaluate the accessibility, usability, reliability and readability of websites available to patients regarding TRUS biopsy of the prostate.

\section{Materials and Methods}

The 5 most commonly used search engines in the United States of America (USA) and the United Kingdom (UK) were identified $[15,16]$ - Google, Bing, Yahoo, Ask and AOL. We performed 3 separate searches on each of these search engines, using the terms: "prostate biopsy", "TRUS biopsy" and "transrectal ultrasound guided biopsy of the prostate". These terms of varied elaboration and complexity were chosen to reflect most common and accepted language among patients, with the aim to maximise search results. No advanced search settings were utilised. The first 20 websites from each search was selected for analysis. This limit was chosen as evidence suggests that users rarely look beyond the first page of search engine results, which contains 10 websites [17]. Searches were performed on the 27th of May 2013. Websites that were duplicates, irrelevant, inaccessible or not primarily text-based (e.g. www.youtube.com) were excluded.

Website authorship was independently determined by 2 authors (CR and GN). The websites were categorized as being produced by an academic institution, a health related charity, a government agency, a non-academic affiliated institution, a media source, a health information website or other. The country of origin of each website and the presence or absence of advertisements was also noted.

\section{Quality Assessment}

Quality assessment was performed using the Minervation Validation Instrument for Health Care Websites (LIDA tool). The
LIDA tool is a validated instrument produced by Minnervation [18], an Oxford (UK) based company that offer consultancy services to improve the quality of healthcare websites. The LIDA tool has been used to assess the quality of websites on various subjects including coronary angioplasty [19], colorectal cancer [20], and uterine artery embolization [21]. It consists of a 41-point inspection that score websites across 3 domains; accessibility ( 0 $60)$, usability (0-54), and reliability (0-51) with the addition of an overall score. Each site was assigned a total score (0-165), which was the sum of the score in each of the domains. A score $>90 \%$ was suggestive of a good result, while scores $<50 \%$ represent poor results. Scoring is on a 4-point scale $(0=$ never, $1=$ sometimes, 2 $=$ mostly, $3=$ always).

The criteria of the aforementioned instrument are as follows: 1) Accessibilty: "Is the website's content accessible to consumers, including those with disabilities"? The LIDA tool checks the website's compliance with legal accessibility standards. This section is performed using the online component of the tool. In addition, access to each individual websites was tested across a variety of operating systems (Windows and Macintosh) and browsers (Microsoft Internet explorer, Mozilla Firefox and Apple Safari). 2) Usability: "Can the user find the information they need?" This section of the tool assesses website clarity, functionality and consistency. Points are allocated for provision of an effective search facility, interactivity and integration of non-textual media. 3) Reliability: "Does the site provide comprehensive, relevant and unbiased information?" This section of the tool assesses the websites' conflicts of interest, content production and output of content. Points are allocated for frequent content update, reference to original sources of information and consistency with current best practice.

\section{Website Certification}

Websites were examined for the presence or absence of 2 commonly used website certificates; The Health on the Net Foundation Code of Conduct (HONCode) and The Information Standard. The HONCode is issued by The Health on the Net Foundation [22], a United Nations approved agency. The Information Standard is a certification scheme commissioned by the English National Health Service [23]. These certificates are awarded to websites that meet required standards of health information reliability.

\section{Readability Assessment}

Readability refers to the ease at which text can be read and understood. Readability was assessed using 2 validated readability tools - the Flesch Reading Ease Score (FRES) and the Flesch Kincaid Grade Level (FK Grade Level) [24], which is a validated tool recommended by the National Institutes for Health [25]. The FRES is calculated based on the total words, syllables and sentences of a written passage. The formula generates a readability score $0-100$, with higher scores indicating increased ease of reading and lower scores indicating more difficult text. The FK Grade Level scores text based on the number of words per sentence and the number of syllables per word. It generates a USA school grade level (up to grade 12) at which full comprehension of the text would be expected and is inversely proportional to the FRES. The National Institute for Health recommends an FK Grade level of 6-7 for Health Materials [25]. The first 200 words of the main text from each website were copied into Microsoft Word (Microsoft Word 2008 for MacOSX; Microsoft, Redmond, WA). The text 


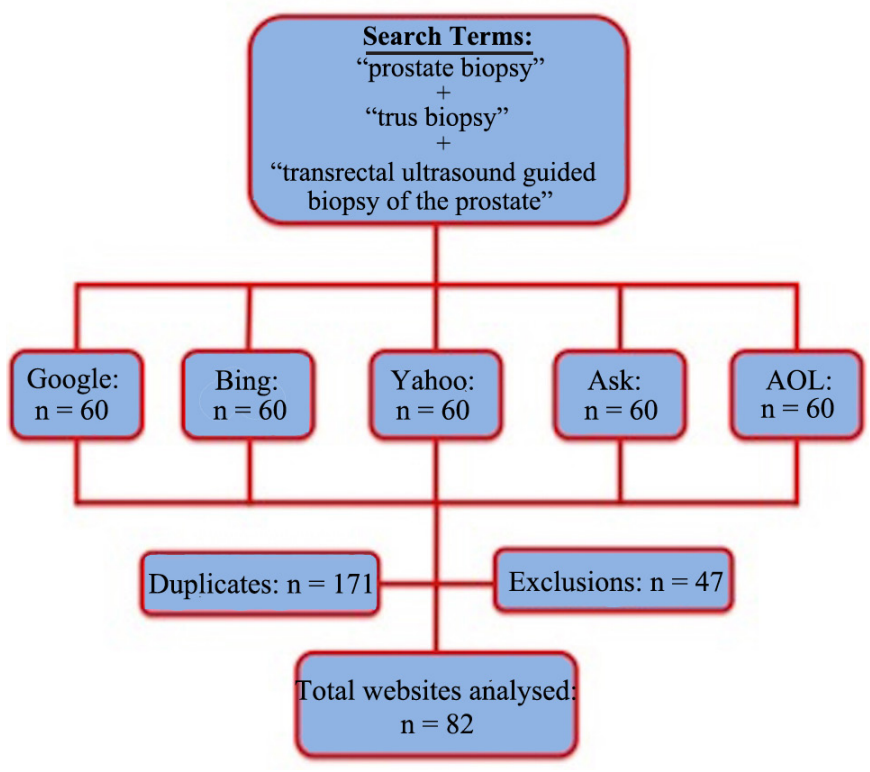

Fig. 1. A demonstration of website identification.

was removed of formatting to ensure accurate readability analysis. The FK grade level was calculated using the spelling and grammar tool in Microsoft Word. This is consistent with practices described in previous studies $[4,26]$.

Statistical analysis was performed using GraphPad Prism Version $6.0^{\circledR}$ (California, USA). ANOVA and unpaired student's t-test were used where appropriate. A p-value $<0.05$ was deemed statistically significant.

\section{Results}

The search yielded 300 websites. Of these, 171 websites were duplicates and were thus excluded. A further 47 websites were excluded as they were irrelevant, inaccessible or not primarily text-based. A total of 82 websites underwent analysis (fig. 1). The websites were categorized according to their declared authorship. Twenty-nine $(35.4 \%)$ websites were produced by academic institutions, $16(19.5 \%)$ by a non-academic institution, $10(12.2 \%)$ by health information websites, $8(9.8 \%)$ by health related charities, $7(8.5 \%)$ by governmental agencies, $7(8.5 \%)$ by media sources and $5(6.1 \%)$ were other (fig. 2). Forty-two $(51.2 \%)$ were produced in the USA, $21(25.6 \%)$ in the UK, $9(11 \%)$ in Australia, $3(3.7 \%)$ in Canada, $1(1.2 \%)$ each in Bosnia and Herzegovina, Columbia, Hong Kong, India, Europe and 2 (2.4\%) were other. Twenty-one $(25.6 \%)$ of the websites had advertisements present on their homepage.

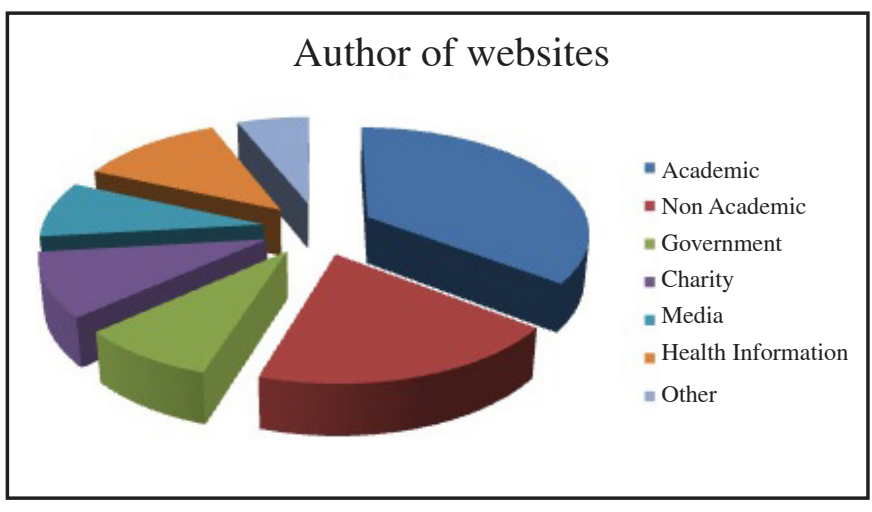

Fig. 2. A representation of website authorship.

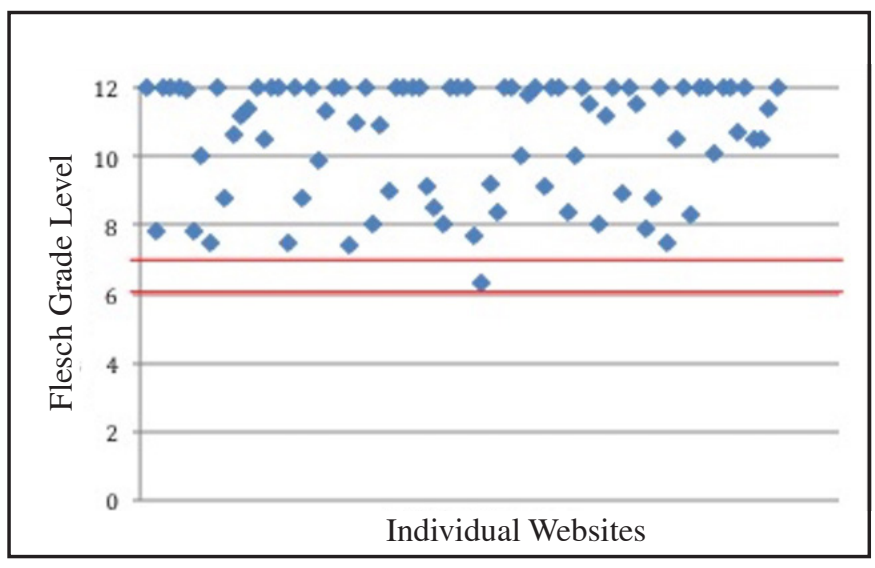

Fig. 3. Flesch Grade Level scores for all websites. The red lines represent a reading level between Grade 6 and 7, which is the recommended upper limit for a health related website by the National Institute of Health.

\section{Website Certification}

Nine $(11 \%)$ of the websites were HONCode certified. Five $(6.1 \%)$ of the websites displayed The Information Standard.

\section{LIDA Tool}

The mean overall LIDA tool score was $109.43 \pm 19.53$ (range: 33-144). There was a significant difference in total mean scores depending on declared authorship categories ( $\mathrm{p}$ 0.001), with health related charity websites scoring highest (mean $122.29 \pm 13.98$ ) and non-academic affiliated institution websites scoring lowest (mean $87 \pm$ 19.76). Concerning each individual facet of the LIDA tool, the mean overall accessibility score was $50.71 \pm$ 8.75. There was no difference regarding accessibility $(p=0.372)$ between the categories. The mean overall 
Table. 1. LIDA Tool scores (total, accessibility, usability, reliability) and Flesch scores (FRES and FK grade level)

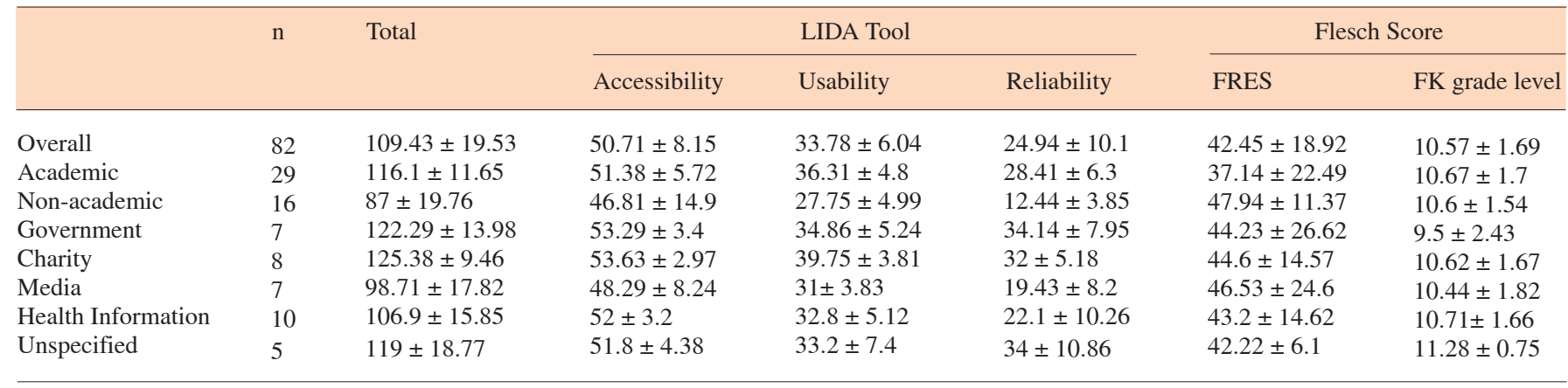

Table. 2. Characteristics of the top 10 ranking websites by LIDA score (anonymised)

\begin{tabular}{|c|c|c|c|c|c|c|c|}
\hline & $\begin{array}{l}\text { Rank by total } \\
\text { LIDA score }\end{array}$ & $\begin{array}{l}\text { Highest search } \\
\text { engine rank }\end{array}$ & Authorship & $\begin{array}{l}\text { Country of } \\
\text { origin }\end{array}$ & $\begin{array}{l}\text { Website } \\
\text { certification }\end{array}$ & Advertisements & $\begin{array}{l}\text { Flesch } \\
\text { grade level }\end{array}$ \\
\hline Website A & 1 & 5 & government & UK & IS & no & 7.7 \\
\hline Website C & 3 & 1 & other & UK & IS, HC & no & 11.4 \\
\hline Website D & 4 & 1 & academic & Europe & none & no & 12 \\
\hline Website E & $=5$ & 18 & academic & Canada & none & no & 12 \\
\hline Website H & $=5$ & 8 & other & USA & none & no & 10.5 \\
\hline Website I & 9 & 1 & academic & USA & $\mathrm{HC}$ & no & 10.6 \\
\hline Website J & $=10$ & 13 & academic & USA & none & yes & 12 \\
\hline Website K & $=10$ & 20 & academic & UK & IS & no & 7.4 \\
\hline Website L & $=10$ & 2 & charity & USA & none & no & 10.9 \\
\hline
\end{tabular}

IS $=$ The information standard; HC $=$ HONCode .

usability score was $33.78 \pm 6.04$, with a significant difference according to authorship ( $p<0.001)$, with health related charity websites scoring highest (mean 39.75 \pm 3.81 ) and non-academic affiliated institution websites scoring lowest (mean $27.75 \pm 4.99$ ). The mean overall reliability score was $24.92 \pm 10.1$, with a significant difference regarding authorship $(\mathrm{p}<0.001)$, with government agency websites scoring highest (mean $34.14 \pm 7.95$ ) and non-academic affiliated institution websites scoring lowest (mean $12.44 \pm 3.85$ ). The individual scores are listed in table 1 and the top 10 ranking websites are listed in table 2 .

\section{Flesch Readability Score}

The mean overall FRES was $42.45 \pm 18.92$. There was no difference in reading score according to authorship ( $\mathrm{p}$ $=0.672$ ). The mean overall FK Grade Level was 10.57 \pm 1.69 (fig. 3), with no difference in FK Grade level according to authorship $(\mathrm{p}=0.698)$.
The presence of advertisements on a website was associated with a lower mean overall LIDA tool score $(102.31 \pm 22.6$ vs. $112.73 \pm 17.16, p=0.024)$. There was no difference with respect to FRES score or FK Grade level ( $p=0.59$ and 0.54 , respectively). There was no difference in overall LIDA tool score, FRES or FK Grade level with the presence of the HONCode or The Information Standard on a website $(\mathrm{p}=0.74,0.91$ and 0.41 , respectively).

\section{Discussion}

The Internet provides a vast source of freely accessible information to patients. The usage of the Internet continues to grow exponentially. The emergence of the Internet with its accessibility has fundamentally changed interaction with patients. The emergence of the "self-educated" patient resulted in a new dynamic to the doctor-patient 
consultation. In 1999 Pautler et al. [27] conducted a survey among a Canadian Cohort of men diagnosed with prostate cancer. They identified that a substantial number of patients (29\% of respondents) had obtained information pertaining to prostate cancer and its treatment via the Internet. It is reasonable to contemplate that this percentage would be much higher today, as a result of the increase in Internet usage since that study was conducted.

The only previously reported evaluation of TRUS biopsy information was done by Shergill et al. [28] in 2010 . Their study specifically evaluated the quality of information in patient leaflets in the North Thames region in the UK, concluding that vital information was lacking. There have however been numerous studies evaluating urology related information websites. Wong et al. [29] evaluated a sample of urological websites based in the USA. They found the reliability of the online information to be poor, with a need for significant improvement from the urology profession. Given the growing debate regarding the role of transperineal prostate biopsy and the role of imaging prior to TRUS biopsy, it is paramount that patients' are appropriately and accurately informed prior to undergoing a TRUS biopsy.

Our study revealed a wide variance in quality of information pertaining to TRUS biopsies. Health related charity websites were of the highest overall quality. However, governmental websites scored highest in reliability. The highest ranking website in respect to quality was one of a UK Governmental Agency. The non-academic affiliated institution's websites were found to have the lowest quality. These largely consisted of private urology clinic websites. In addition, these websites scored particularly poorly in reliability, with information that was often outdated, lacking references and with no stated editorial policy. Furthermore, the presence of advertisements on any website was further predictive of poor quality.

Numerous studies have observed poor information quality in commercially orientated websites, [4, 5, 8]. Our study also observes such an association. The low volume (17\%) of websites that had achieved website certification (HONCode and/or The Information Standard) is concerning. While we did not find a significant association between quality scoring and website certification, it was noted that a high proportion of the top ranking websites had certification.

All website authorship categories scored poorly in readability, with no significant difference between the authorship categories or with website certification. Only a single website adhered to the National Institutes for Health recommendations on readability [25]. This find- ing is of critical importance, as if information is not comprehendible it will not provide any benefit to patients and may instead perpetuate confusion about TRUS biopsies.

"Search engine optimization" has become an important process for websites to obtain a favorable position in search engine results. The quality of content is not a prioritized factor in this process. Nevertheless, in our study $75 \%$ of the websites that scored highest in quality appeared in the first page of at least one of the search engines. A new website quality assessment tool has been proposed by Dunne et al. [30], in which an assessment score has a correlation with ranking in Google Engine Results Pages. This may aide in the design of a medical or health information websites which are of good quality and highly ranked by search engines.

This study outlines several implications on the future direction of clinical practice. A key recommendation made in the study by Pautler et al. in 2001, was that physicians should acquaint themselves with good quality websites that they are comfortable recommending to patients. This recommendation has been echoed in other studies evaluating the Internet information on a variety of common urological conditions and procedures $[8,31]$. We report an anonymized list of the websites that scored highest in this study and their associated characteristics. Many websites analyzed contained quality useful information however required lengthy website navigation to access this information. As a result of awkward website design the appropriate information may be masked from the user. Future websites should marry accurate, up to date information at a level appropriate to the target audience with astute website design in an effort to develop useful accessible information for the patient. Pautler et al. also proposed that the medical community act as an "auditing mechanism" to ensure reliability of medical websites. We feel this recommendation still holds true today. It is therefore disappointing to observe that the websites that scored poorest in terms of accessibility, usability and reliability were websites of non-academic, private urological institutions.

The "Internet era" is well and truly upon us and will continue to bear significance on the quality and delivery of patient care. It is therefore of the utmost importance that physicians engage with the internet and act responsibly as custodians for medical websites.

The present study has a number of limitations that are consistent with previously published Internet based studies. The Internet is a dynamic evolving source of information and therefore content changes rapidly. This study is a static depiction of the current available information 
on the Internet. However, it reflects both the potential benefit and vulnerability that it poses to healthcare of today and the future.

In conclusion, this study demonstrates variability in the quality of information available to Internet users regarding TRUS biopsies. Readability of the websites ex- amined was poor. In the modern era of accessibility to a vast array of uncensored information, physicians must be conscious of patients having distorted views relating to medical procedures. The ideal website will merge high quality, readable and easily accessible information, with responsible input from physicians.

\section{References}

1 Blanchett KD: Transforming the medical information landscape: think tank explores new media applications. BJU Int 2011;107(8): ii-v.

2 Rainie L, Horrigan J, Lenhart A, Spooner T, Burke M, Lewis O, Carter C: The online health care revolution: how the Web helps Americans take better care of themselves. Washington, DC: The Pew Internet \& American Life Project. Available at: http://www. pewinternet.org.

3 Nason GJ, Baker JF, Byrne DP, Noel J, Moore D, Kiely PJ: Scoliosis-specific information on the internet. Spine 2012;37(21):E1364 1369.

4 Killeen S, Hennessey A, Hassan El Y, Killeen K, Clarke N, Murray K, Waldron B: Gastric cancer-related information on the internet: incomplete, poorly accessible, and overly commercial. Am J Surg 2011;201(2):171178.

5 Yeung TM, D'Souza ND: Quality analysis of patient information on surgical treatment of haemorrhoids on the internet. Ann R Coll Surg Engl 2013;95(5):341-344.

6 Taylor H: Number of 'cyberchondriacs' adults going online for health information has plateaued or declined. Harris Interactive. Available at: http://www.harrisinteractive. com/vault/HI-Health CAreNews2008Vol8 Iss08.pdf. Accessed November 5th, 2013.

7 Nan X, Madden K: HPV vaccine information in the blogosphere: how positive and negative blogs influence vaccine-related risk perceptions, attitudes, and behavioral intentions. Health Commun 2012;27(8):829-836.

8 Nason GJ, Tareen F, Quinn F: Hydrocele on the web: An evaluation of internet-based information. Scand J Urol 2013;47(2):152157.

9 Bowes P, Stevenson F, Ahluwalia S, Murray E: 'I need her to be a doctor': patients' experiences of presenting health information from the internet in GP consultations. Br J Gen Pract 2012;62(604):e732-738.

10 Hungerford DS: Internet access produces misinformed patients: managing the confusion. Orthopedics 2009;32(9).

11 Astraldi A: Diagnosis of cancer of the prostate; biopsy by rectal route. Urol Cutan Rev 1937;41:421-427.
12 Heidenreich A, Bastian PJ, Bellmunt J, Bolla M, Joniau S, van der Kwast T, Mason M, Matveev V, Wiegel T, Zattoni F, Mottet $\mathrm{N}$ : EAU guidelines on prostate cancer. Part 1: screening, diagnosis, and local treatment with curative intent-update 2013. Eur Urol 2014;65:124-137.

13 Bostwick DG, Meiers I: Prostate biopsy and optimization of cancer yield. Eur Urol 2006;49(3):415-417.

14 Lee G, Attar K, Laniado M, Karim O. Safety and detailed patterns of morbidity of transrectal ultrasound guided needle biopsy of prostate in a urologist-led unit. Int Urol Nephrol 2006;38(2):281-285.

15 Available from URL: http://www.comscore. com/Insights/Press_Releases/2013/5/com Score_Releases_April_2013_US_Search_ Engine_Rankings. Accessed 25th May 2013.

16 Available from URL: http://theeword. co.uk/seomanchester/gains_all_round_in_ april_2013_search_market_share.html. Accessed May 25th, 2013.

17 Eysenbach G, Kohler C: How do consumers search for and appraise health information on the world wide web? Qualitative study using focus groups, usability tests, and in-depth interviews. BMJ 2002;324(7337):573-577.

18 Available from URL: http://www.minervation.com. Accessed May 25th, 2013.

19 Kirthi V, Modi BN: Coronary angioplasty and the internet: what can patients searching online expect to find? J Interv Cardiol 2012;25(5):476-481.

20 Grewal P, Alagaratnam S: The quality and readability of colorectal cancer information on the internet. Int J Surg 2013;11(5):410 413.

21 Tavare AN, Alsafi A, Hamady MS: Analysis of the quality of information obtained about uterine artery embolization from the internet. Cardiovasc Intervent Radiol 2012;35(6):1355-1362.

22 Boyer C, Baujard V, Geissbuhler A: Evolution of health web certification through the HONcode experience. Stud Health Technol Inform 2011;169:53-57.

23 Available from URL: http://www.theinformationstandard.org. Accessed May 25th, 2013.
24 Kincaid JP, Fishburne RP, Rogers RL, Chissom BS: Derivation of new readability formulas (Automated Readability Index, Fog Count, and Flesch Reading Ease Formula) for Navy enlisted personnel. Research Branch report 8-75. Memphis: Naval Air Station, February 1975.

25 Available from URL: http://www.nlm.nih. gov/medlineplus/etr.html. Accessed September 29th, 2013.

26 Ellimoottil C, Polcari A, Kadlec A, Gupta G: Readability of websites containing information about prostate cancer treatment options. J Urol 2012;188(6):2171-2176.

27 Pautler SE, Tan JK, Dugas GR, Pus N, Ferri M, Hardie WR, Chin JL: Use of the internet for self-education by patients with prostate cancer. Urology 2001;57(2):230-233.

28 Shergill I, Bahl K, Farjad M, Phipps C, Fowlis G: Patient information leaflets for transrectal ultrasound guided prostate biopsy: Results of North Thames deanery survey. BMC Res Notes 2010;3(1):27.

29 Wong L-M, Yan H, Margel D, Fleshner NE: Urologists in cyberspace: A review of the quality of health information from American urologists' websites using three validated tools. Can Urol Assoc J 2013;7(3-4):100 107.

30 Dunne S, Cummins NM, Hannigan A, Shannon B, Dunne C, Cullen W: A method for the design and development of medical or health care information websites to optimize search engine results page rankings on Google. J Med Internet Res 2013;15(8):e183.

31 Fast AM, Deibert CM, Boyer C, Hruby GW, McKiernan JM: Partial nephrectomy online: a preliminary evaluation of the quality of health information on the Internet. BJU International 2012;110(11b):E765-769. 